\title{
Predictive models for strength enhancements in cold-formed structural sections
}

\author{
B. Rossi \\ University of Liège, Liège, Belgium \\ S. Afshan \& L. Gardner \\ Imperial College London, London, UK
}

\begin{abstract}
Cold-formed structural sections are manufactured at ambient temperature and hence undergo plastic deformations which result in an increase in the yield stress and ultimate stress, but reduced ductility. This paper begins with a comparative study of existing predictive models to harness this strength increase. Modifications to the existing models are then made and an improved model is presented. Tensile coupon tests from the literature have been used to validate and compare the predictive models. A wide range of structural section types from both cold-rolling and press-braking fabrication processes and structural materials, including various grades of carbon steel and stainless steel, have been considered.
\end{abstract}

\section{INTRODUCTION}

Cold-formed structural sections are widely used in construction, offering high strength and stiffness-toweight ratios. Structural elements in a range of section shapes - tubular sections, including the familiar square, rectangular and circular hollow sections and the recently added elliptical hollow sections, and open sections such as angles, channels and lipped channels - are commonly used in building design. Cold-formed structural sections are manufactured at ambient temperature and hence undergo plastic deformations, which occur during both the sheet rolling and cross-section forming processes, causing strain hardening of the material. Upon application of stress, the strain hardened or cold-worked material follows a new loading path with an increased yield stress and ultimate stress, but reduced ductility. In metallic materials with a distinctly defined yield point, such as carbon steels, the stress-strain behaviour becomes rounded following the cold-forming process. Non-uniformity in the material properties around cold-formed sections also exist, due to the varying level of plastic strain experienced, with the corner regions being the most influenced. Materials, such as stainless steel, with rounded stress-strain behaviour and significant strain hardening show a more pronounced response to cold-working.

With increasing emphasis being put on the sustainable use of resources, fully exploiting material properties in structural design is paramount. The performance of finite element models is also often highly sensitive to the prescribed material parameters, making an accurate representation of the material characteristics essential. Therefore, developing suitable predictive models for harnessing the increases in material strength caused by plastic deformations, experienced during the cold-forming production routes, is required. In this paper, predictive models from the literature for determining the strength enhancement observed in cold-formed metallic sections are reviewed. Two recently proposed predictive models, developed by Cruise and Gardner (2008) and Rossi (2008), have been assessed extensively. Improvements to the existing models have been made and a new predictive model is presented. Results from tensile coupon tests from existing experimental programs have been gathered and used to validate the predictions from the models. Comparisons between the presented predictive equations have been made. The collated database covers a range of structural section types - square hollow sections (SHS), rectangular hollow sections (RHS), angles, lipped channels and hollow flange channel sections from both cold-rolling and press-braking fabrication processes - and structural materials, namely carbon steel and stainless steel (EN 1.4301, 1.4306, 1.4318, 1.4016, 1.4003, 1.4512 and 1.4162).

\section{PRODUCTION ROUTES}

Cold-rolling and press-braking are the two methods commonly employed in the manufacture of light 
gauge cold-formed structural sections. In pressbraking the sheet material is formed into the required shape by creating individual bends along its length. It is a semi-automated process used to produce open sections, such as angles and channels, in limited quantities. Air press-braking, where elastic spring back is allowed by over-bending the material, is more commonly adopted than coin press-braking, where the die and the tool fit into one another. Coldrolling is an automated continuous bending process in which the gradual deformation of the uncoiled metal sheet through a series of successive rollers produces the final cross-section profile.

In case of tubular box sections, the flat metal sheet is first rolled into a circular tube and is welded closed. It is subsequently deformed into a square or rectangle by means of dies. The tube's cross-section is initially circular whereas the cross-section at the end of the process is a square or rectangle with round corners. Finite element models with contact boundary conditions allow simulation of this continuous process, but are rather complex and time consuming and require sophisticated software.

\section{PREDICTIVE MODELS}

\subsection{Literature review}

Early studies of the strength enhancement in the corner regions of cold-formed carbon steel sections were carried out by Karren (1967). A power model to predict the strength increases in the corner regions of cold-formed sections, in terms of the yield stress of the unformed sheet material and the internal corner radius to thickness ratio was proposed. The model was developed based on available test data, including specimens formed by both cold-rolling and press-braking processes. The author suggested that since the corner regions typically represent $5 \%$ to $30 \%$ of the total cross-sectional area, the influence of the enhanced corner strength should be incorporated in structural calculations. Coetzee et al. (1990) performed an experimental study into strength enhancements of cold-formed stainless steel sections. Material tests on press-braked lipped channel sections of three stainless steel grades (EN 1.4301, 1.4401 and 1.4003) were conducted. Karren's expression was later modified by van den Berg and van der Merwe (1992) on the basis of Coetzee et al.'s test data and further test data on stainless steel single press-braked corner specimens in grades EN 1.4301, 1.4016, 1.4512 and 1.4003. Gardner and Nethercot (2004) studied test data from cold-rolled box sections and observed a linear relationship between the $0.2 \%$ proof strength of the corner regions and the ultimate strength of the flat faces.

Ashraf et al. (2005) analysed all stainless steel test results, from a variety of fabrication processes, to investigate the application of the predictive equations proposed by van den Berg and van der Merwe (1992). Comparisons of the predicted strength and the test results showed that modifications to the models were required. Three empirical predictive models for the evaluation of the corner yield strength were proposed. Two power models based on the properties $(0.2 \%$ proof strength and the ultimate tensile strength) of the unformed sheet material were developed to predict the corner $0.2 \%$ proof strength of both cold-rolled and press-braked sections. The linear expression proposed by Gardner and Nethercot (2004), to predict the $0.2 \%$ proof strength of the corners in cold-rolled box sections was also recalibrated. Furthermore, in order to obtain a full insight into the influence of cold-work on the corner material properties, an equation to predict the ultimate strength of the corner material was developed.

Cruise and Gardner (2008) later recalibrated the Ashraf et al. (2005) expressions in light of further stainless steel experimental data and proposed two revised expressions to predict the enhanced corner strength of press-braked and cold-rolled sections. In addition, expressions for evaluating the $0.2 \%$ proof stress and the ultimate tensile stress of the flat faces of cold-rolled box sections were developed. Similarly, based on corner material test results on structural carbon steel box sections, Gardner et al. (2010) modified the predictive model given in the AISI Specification for the Design of Cold-formed Steel Structural Members (2002). Values of the coefficients in the predictive equation were proposed that enabled the model to be applied to the assessment of the enhanced corner strength of cold-rolled square and rectangular hollow sections. An alternative formula to evaluate the enhanced $0.2 \%$ proof strength in the flat faces and corner regions of cold-formed sections, using the properties of the unformed sheet material and the final cross-section geometry, was proposed by Rossi (2008). The proposed model may be applied to a range of nonlinear metallic materials.

\subsection{Cruise and Gardner (2008) predictive model}

Cruise and Gardner (2008) carried out an extensive experimental program on cold-formed stainless steel structural sections, produced from both cold-rolling and press-braking production routes. Based on the experimental results, including tensile coupon tests and hardness tests, the distributions of the $0.2 \%$ proof strength and ultimate strength around a series of cold-rolled box sections and press-braked angle sections were identified. The generated test data were combined with all other available published experimental data and used to develop models for predicting the strength enhancements around stainless steel sections due to cold-forming. The experimental observations showed that, for press- 
braked sections, the enhancements are confined to the corner regions, whereas cold-rolled box sections also exhibited significant strength increases in the flat faces, indicating that the flat faces in cold-rolled box sections also experience plastic deformations during forming. New models were therefore proposed to predict the strength enhancements in the flat faces of cold-rolled box sections. Expressions for the $0.2 \%$ proof stress $\sigma_{0.2, \text { f,pred }}$ and the ultimate tensile stress $\sigma_{u, f, p r e d}$, Eqs. (1) and (2) respectively, were provided, in which $\mathrm{t}, \mathrm{b}$ and $\mathrm{d}$ are the section thickness, breadth and depth respectively, and $\sigma_{0.2 \text {,mill }}$ and $\sigma_{u \text {,mill }}$ are the $0.2 \%$ proof stress and ultimate tensile stress of the unformed material, as provided by the mill certificate.

$$
\begin{gathered}
\sigma_{0.2, \text { f,pred }}=\frac{0.85 \sigma_{0.2, \text { mill }}}{-0.19+\frac{1}{12.42\left(\frac{\pi \mathrm{t}}{2(\mathrm{~b}+\mathrm{d})}\right)+0.83}} \\
\sigma_{\mathrm{u}, \mathrm{f}, \text { pred }}=\sigma_{\mathrm{u}, \text { mill }}\left(0.19\left(\frac{\sigma_{0.2, \mathrm{f}, \mathrm{pred}}}{\sigma_{0.2, \text { mill }}}\right)+0.85\right)
\end{gathered}
$$

Existing literature models were also modified to predict the strength enhancement in the corner regions of cold-rolled and press-braked stainless steel sections. The simple power model proposed by Ashraf et al. (2005) was recalibrated based on a more comprehensive experimental database to predict the $0.2 \%$ proof stress of the corners in pressbraked sections. For cold-rolled sections, the model presented in Gardner and Nethercot (2004) and later recalibrated by Ashraf et al. (2005), providing a linear relationship between the $0.2 \%$ proof stress of the formed corners and the ultimate strength of the flat faces, was again updated. The proposed expressions for the corner strength enhancement $\sigma_{0.2, \text { c,pred }}$ are given by Eqs. (3) and (4) for pressbraked sections and cold-rolled sections, respectively, in which $R_{i}$ is the internal corner radius. The experimental data also indicated that, the corner strength enhancement extends beyond the curved corner region for cold-rolled sections, and it is confined to the corner region for press-braked sections. It was therefore proposed that Eq. (4) should be used to predict a uniform strength enhancement for the corner region plus an extension of $2 t$, where $t$ is the material thickness, beyond the corner radius into the flat faces of the section.

For press-braked section:

$$
\sigma_{0.2, \mathrm{c}, \text { pred }}=\frac{1.673 \sigma_{0.2, \text { mill }}}{\left(\frac{\mathrm{R}_{\mathrm{i}}}{\mathrm{t}}\right)^{0.126}}
$$

For cold-rolled section:

$$
\sigma_{0.2, \mathrm{c}, \text { pred }}=0.83 \sigma_{\mathrm{u}, \mathrm{f} \text {,pred }}
$$

\subsection{Rossi (2008) predictive model}

Rossi (2008) examined the through-thickness residual stress distributions and strength enhancements induced during cold-forming of sections composed of nonlinear metallic materials. The proposed model for predicting the cold-work strength enhancement is essentially based on the determination of the plastic strains caused during the fabrication process and evaluation of the corresponding stresses, through an appropriate material model. The cold-rolling fabrication process was broken down into four key steps: (A) coiling of the sheet material, (B) uncoiling of the sheet material, (C) forming into a circular section and (D) subsequent deforming into a square or rectangular section.

The flat faces of cold-rolled hollow sections were thus assumed to undergo coiling and uncoiling in the rolling direction followed by bending and unbending in the direction perpendicular to the rolling direction. Step $\mathrm{C}$ was considered to have the greatest influence on strength enhancement in the flat faces of cold-rolled box sections and was used as the dominant stage for subsequent analysis. For the corner regions, in both cold-rolled and press-braked sections, the final formation of the corner was considered as the dominant stage of the process.

The induced plastic strains associated with the dominant stages of the flat face and corner forming processes were determined. Assuming pure bending, the strain experienced by the section face during the formation of the circular tube (step C) was taken as $\varepsilon_{\mathrm{f}}=(\mathrm{t} / 2) / \mathrm{R}_{\mathrm{f}}$, where $\mathrm{R}_{\mathrm{f}}$ is the radius of the circular tube and can be expressed in terms of the section geometry - see Figure 1 - leading to $\varepsilon_{\mathrm{f}}=\pi \mathrm{t} / 2(\mathrm{~b}+\mathrm{d})$. Similarly, the strain induced during corner forming was given as $\varepsilon_{\mathrm{c}}=(\mathrm{t} / 2) / \mathrm{R}_{\mathrm{c}}$, where $\mathrm{R}_{\mathrm{c}}=\mathrm{R}_{\mathrm{i}}+\mathrm{t} / 2$. Note that these are essentially the same strains considered by Cruise and Gardner (2008).

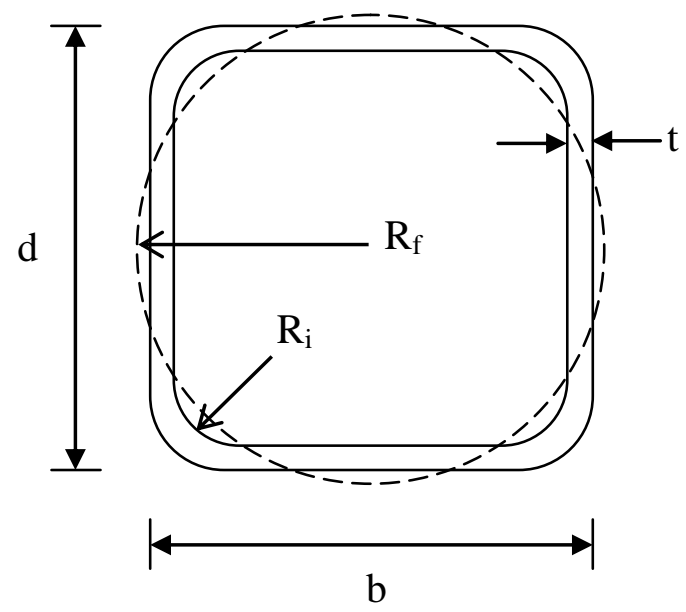

Figure 1. Definition of symbols for SHS and RHS. 
The inverted compound Ramberg-Osgood material model, proposed by Abdella (2006) was employed within the predictive model to mimic the stress-strain response of the unformed sheet material, with key points obtained from the mill certificate. The resulting predictive model (Rossi, 2008) is given by Eq. (5). The proposed formula may be used to evaluate the strength enhancement $\sigma_{0.2, \mathrm{f} \text { or } \mathrm{c} \text {, pred }}$ in the flat faces of cold-rolled box sections and the corner regions of both cold-rolled sections and pressbraked sections, based on the appropriate radius: $R_{f}$ $=(b+d) / \pi$ for flat faces and $R_{c}=R_{i}+t / 2$ for the corner regions.

$$
\frac{\sigma_{\mathrm{u}, \text { mill }}}{\sigma_{0.2, \text { for } \mathrm{c} \text {, pred }}-\sigma_{0.2, \text { mill }}}=\mathrm{C}_{1}\left(\frac{\mathrm{R}}{\mathrm{t} / 2}\right)+\mathrm{C}_{2}\left(\frac{\mathrm{R}}{\mathrm{t} / 2}\right)^{\alpha}
$$

where,

$$
\begin{aligned}
& \mathrm{C}_{1}=\frac{\varepsilon_{\mathrm{t}, 0.2}}{\mathrm{r}_{2}} \frac{\sigma_{\mathrm{u}, \text { mill }}}{\sigma_{0.2, \text { mill }}} \\
& \mathrm{C}_{2}=\frac{\left(\mathrm{r}^{*}-1\right) \varepsilon_{\mathrm{t}, 0.2}}{\mathrm{r}_{2}\left(\varepsilon_{\mathrm{u}}-\varepsilon_{\mathrm{t}, 0.2}\right)^{\mathrm{p}^{*}}} \frac{\sigma_{\mathrm{u}, \text { mill }}}{\sigma_{0.2, \text { mill }}}
\end{aligned}
$$

where, $\mathrm{r}_{2}=\mathrm{E}_{0.2} \varepsilon_{\mathrm{t}, 0.2} / \sigma_{0.2}, \mathrm{E}_{0.2}=\sigma_{0.2} \mathrm{E} /\left(\sigma_{0.2}+0.002 \mathrm{nE}\right)$, $\mathrm{r}^{*}=\mathrm{E}_{0.2}\left(\varepsilon_{\mathrm{u}}-\varepsilon_{\mathrm{t}, 0.2}\right) /\left(\sigma_{\mathrm{u}}-\sigma_{0.2}\right), \mathrm{p}^{*}=\mathrm{r}^{*}\left(1-\mathrm{r}_{\mathrm{u}}\right) /\left(\mathrm{r}^{*}-1\right)$, $\mathrm{r}_{\mathrm{u}}=\mathrm{E}_{\mathrm{u}}\left(\varepsilon_{\mathrm{u}}-\varepsilon_{\mathrm{t}, 0.2}\right) /\left(\sigma_{\mathrm{u}}-\sigma_{0.2}\right), \mathrm{E}_{\mathrm{u}}=\mathrm{E}_{0.2} /\left[1+\left(\mathrm{r}^{*}-1\right) \mathrm{m}\right]$, $\mathrm{m}=1+3.5 \sigma_{0.2} / \sigma_{\mathrm{u}}, \alpha=1-\mathrm{p}^{*}$ and $\varepsilon_{\mathrm{t}, 0.2}=0.002+\sigma_{0.2} / \mathrm{E}$

\section{COMPARISONS OF EXSISTING PREDICTIVE MODELS}

\subsection{Experimental database}

In order to assess the wider applicability of the predictive models presented in Sections 3.2 and 3.3, tensile coupon data from a broad spectrum of existing testing programs have been gathered. The collated database covers a range of structural section types - SHS, RHS, angles, lipped channel sections (LCS) and hollow flange channel sections (HFCS) from both cold-rolling and press-braking fabrication processes, as illustrated in Figure 2, and a range of structural materials including carbon steel grades and austenitic (EN 1.4301, 1.4306, 1.4318), ferritic (EN 1.4016, 1.4003, 1.4512) and lean duplex (EN 1.4162) stainless steel grades. In order to investigate the strength enhancement due to face forming processes in cold-rolled sections, reported tensile coupon tests for this portion of the section have been used. Table 1 provides a summary of the collected database for the flat faces of the cold-rolled sections analysed herein. Based on the available published corner test data, for both cold-rolled and press-braked sections, the performance of the predictive models for corners has also been assessed. The compiled database for corner coupon tests considered in this study is summarized in Table 2.

The collected information includes the section geometric dimensions, mill certificate material properties $-\sigma_{0.2 \text {,mill }}$ and $\sigma_{\mathrm{u} \text {,mill }}$ - and the measured material properties of the formed sections - the $0.2 \%$ proof stress $\sigma_{0.2 \text {,test }}$ and the ultimate tensile stress $\sigma_{u, \text { test }}$. For cold-formed sections, the mill test is carried out on sheet material prior to section forming and the results are supplied by the manufacturer. The Ramberg-Osgood material model parameters, required for the Rossi (2008) model, were sourced from Ashraf et al. (2006) and Rasmussen (2003), with the relevant material properties obtained from, EN 1993-1-1 (2005) for carbon steel sections and EN 10088-1 (2005) for stainless steel sections.
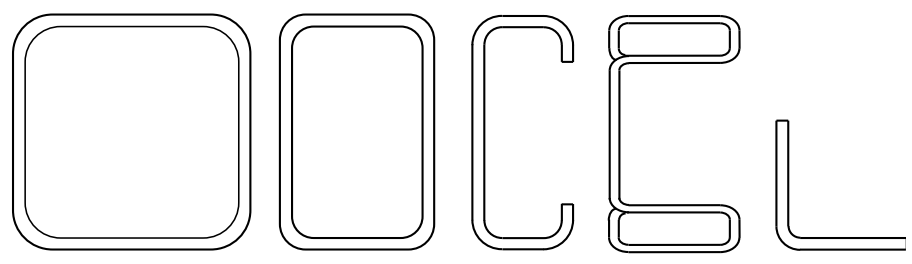

Figure 2. Variety of cold-formed cross-sections considered in this study.

Table 1. Summary of database for coupon tests on flat material in cold-rolled sections from literature.

\begin{tabular}{lll}
\hline Reference & Material & Section \\
\hline Gardner et al. (2010) & CS (S235) & SHS,RHS \\
Guo et al. (2007) & CS (S235) & SHS,RHS \\
Niemi (1990) & CS (S355) & SHS \\
Zhu \& Wilkinson (2007) & CS $^{*}$ & HFCS \\
\hline Ala-Outinen (2007) & SS(1.4301) & SHS \\
Cruise (2007) & SS (1.4301) & SHS,RHS \\
Gardner (2002) & SS (1.4301) & SHS,RHS \\
Gardner et al. (2006) & SS (1.4318) & SHS,RHS \\
Hyttinen (1994) & SS (1.4301) & SHS \\
Rasmussen \& Hancock (1993) & SS (1.4306) & SHS \\
Talja \& Salmi (1995) & SS (1.4301) & SHS \\
Afshan \& Gardner (2012) & SS (1.4003) & SHS,RHS \\
Hyttinen (1994) & SS (1.4003) & SHS \\
Hyttinen (1994) & SS (1.4512) & SHS \\
Theofanous \& Gardner (2010) & SS (1.4162) & SHS,RHS \\
*Material grade was not reported. & &
\end{tabular}

Table 2. Summary of database for coupon tests on corner material from literature.

\begin{tabular}{lll}
\hline Reference & Material & Section \\
\hline Gardner et al. (2010) & CS (S235) & SHS,RHS \\
Guo et al. (2007) & CS (S235) & SHS,RHS \\
Niemi (1990) & CS (S355) & SHS \\
Zhu \& Wilkinson (2007) & CS & HFCS \\
\hline Ala-Outinen (2007) & SS (1.4301) & SHS \\
Coetzee et al. (1990) & SS (1.4301) & LCS \\
Coetzee et al. (1990) & SS (1.4401) & LCS
\end{tabular}


Cruise (2007)

Cruise (2007)

Gardner (2002)

Garddner et al. (2006)

Lecce \& Rasmussen (2005)

Rasmussen \&Hancock (1993)

van den Berg \& van der Merwe

(1992)

Afshan \& Gardner (2012)

Coetzee et al. (1990)

Lecce \& Rasmussen (2005)

Lecce \& Rasmussen (2005)

van den Berg \& van der Merwe (1992)

van den Berg \& van der Merwe (1992)

van den Berg \& van der Merwe (1992)

Theofanous \& Gardner (2010)

*Material grade was not reported.

\subsection{Comparison of predictive models}

This section provides a broad comparison, in terms of both the accuracy of the predictions and the ease of use, of the two predictive models. Numerical comparisons, including the mean and coefficient of variation $(\mathrm{COV})$, of the two predictive models with the test data, in terms of the predicted strength to the test strength ratio, are presented in Tables 3 and 4 for flat faces and corner regions, respectively. Although the proposed predictive model for flat faces of cold-rolled sections provided by Cruise and Gardner (2008) was calibrated only for stainless steel, it has also been applied herein to carbon steel test data for comparison purposes and the results are shown in Table 3 in brackets.

Analysis of the results shows that for the flat faces of cold-rolled stainless steel sections, the predictive model from Rossi (2008) is able to predict more accurate results, in terms of the mean value, than the predictive equation proposed by Cruise and Gardner (2008) but, has higher scatter. The results for the corner regions show that for stainless steel, the Cruise and Gardner (2008) model offers more accurate prediction of the test data with lower scatter. Also, Rossi (2008) and the modified AISI (Gardner et al. 2010) predictions for the corner strength enhancements of carbon steel sections are in good agreement, with the former showing a lower scatter of 0.09 .

As far as the flat faces of cold-rolled sections are concerned, both models use the same measure of cold-work induced strain in their formulations, but different material models. The Rossi (2008) model employs the compound Ramberg-Osgood material model whereas, Cruise and Gardner (2008) assume a linear hardening material behaviour for stainless steel with the material model incorporated into the model coefficients. As a result, while the Rossi (2008) predictive model may be applied to any structural section of non-linear material, the Cruise and Gardner (2008) model is specific to structural sections with the material for which the models were calibrated against, which included austenitic stainless steel grade EN 1.4301.

Due to the complicated mathematical form and the number of input parameters required to evaluate the cold-work induced strength enhancement from Rossi's (2008) predictive equation, it is lengthy to implement in design calculations. In order to overcome the shortcomings of the two predictive models, a new predictive model is developed in the next section.

Table 3. Comparison of the predictive models for flat faces of cold-rolled sections.

\begin{tabular}{llcc}
\hline Predictive model & & $\begin{array}{c}\text { Cruise \& } \\
\text { Gardner (2008) }\end{array}$ & Rossi (2008) \\
\hline \multirow{2}{*}{ All } & Mean & 1.09 & 0.96 \\
& COV & 0.20 & 0.20 \\
\hline \multirow{2}{*}{ Carbon steel } & Mean & $(1.25)$ & 0.94 \\
& COV & $(0.22)$ & 0.16 \\
\hline \multirow{2}{*}{ Stainless steel } & Mean & 1.06 & 0.97 \\
& COV & 0.18 & 0.21 \\
\hline
\end{tabular}

Table 4. Comparison of the predictive models for corner regions of cold-formed sections.

\begin{tabular}{llcc}
\hline Predictive model & & $\begin{array}{c}\text { Cruise \& Gardner } \\
\text { (2008); Gardner } \\
\text { et al. (2010) }\end{array}$ & Rossi (2008) \\
\hline \multirow{2}{*}{ All } & Mean & 0.98 & 1.04 \\
& COV & 0.11 & 0.14 \\
\multirow{2}{*}{ Carbon steel } & Mean & 0.95 & 0.95 \\
& COV & 0.10 & 0.09 \\
\hline \multirow{2}{*}{ Stainless steel } & Mean & 0.98 & 1.05 \\
& COV & 0.12 & 0.14 \\
\hline
\end{tabular}

\section{EXTENSION OF PREDICTIVE MODELS}

\subsection{Introduction}

In this section a simple and accurate method for predicting the strength enhancement in cold-formed structural sections is presented. The model development is based on the same concept as used in the Rossi (2008) predictive model, which involves the determination of the cold-work induced plastic strain followed by the evaluation of the corresponding stress from the stress-strain response of the unformed sheet material, using an appropriate material model. Given the scatter in the test data, see Figures 3 and 4 for flat faces and corner regions, respectively, and the assumptions made in simplifying the forming processes, using a simple material model, in place of the compound Ramberg-Osgood model, is deemed more appropriate. In addition, analysis of the results shows that the plastic strain from both the 


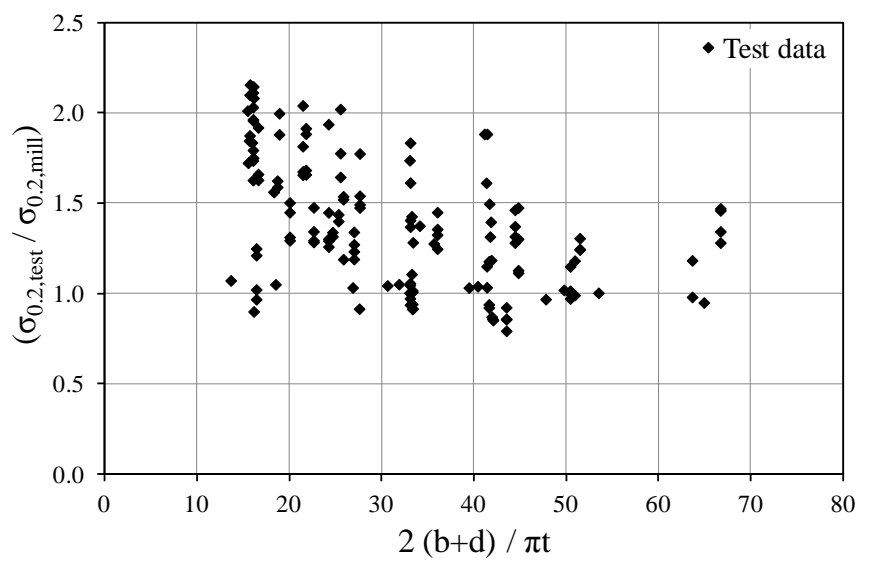

Fig. 3. Normalized measured $0.2 \%$ proof stress for the flat faces of cold-rolled sections.

sheet forming and cross-section forming processes contribute to the overall strength enhancement of the flat faces of cold-rolled box sections.

\subsection{Material stress-strain models}

In order to represent the stress-strain response of the unformed sheet material, the suitability of a power law model and a tri-linear material model with strain hardening, Eqs. 8 and 9, respectively, have been assessed. The parameters which define each model are based on the key material properties from the mill certificate.

The power law model parameters, $a$ and $b$, are calibrated such that it passes through the $0.2 \%$ proof stress $\left(\varepsilon_{\mathrm{t}, 0.2}, \sigma_{0.2}\right)$ and the ultimate stress $\left(\varepsilon_{\mathrm{u}}, \sigma_{\mathrm{u}}\right)$ points. The model's inability to provide a good fit to the actual stress-strain response at low strains will not influence the predicted strength due to the relatively large magnitude of the plastic strains induced during cold-forming processes. The first stage of the tri-linear model has a slope E, taken as the material initial Young's modulus, up to the yield point, defined as the $0.2 \%$ proof stress and the corresponding elastic strain $\varepsilon_{0.2}=\sigma_{0.2} / \mathrm{E}$. The strain hardening slope is determined as the slope of the line passing through the defined yield point $\left(\varepsilon_{0.2}, \sigma_{0.2}\right)$ and a specified maximum point $\left(\varepsilon_{\max }, \sigma_{\max }\right)$ with $\varepsilon_{\max }$ taken as $0.5 \varepsilon_{\mathrm{u}}$, where $\varepsilon_{\mathrm{u}}$ is the ultimate tensile strain, and $\sigma_{\max }$ is taken as the ultimate tensile stress $\sigma_{\mathrm{u}}$. A similar approach has been recommended in EN 1999-1-1 (2007) for modelling the stress-strain response of aluminium alloys. In order to prevent significant over-predictions of strength at large strains, a maximum stress limit equal to the ultimate tensile stress $\sigma_{\mathrm{u}}$ has been added. No strength enhancement would result from strains less than the yield strain; hence the initial part of the model will not be used for strength enhancement predictions. The ultimate tensile strain $\varepsilon_{\mathrm{u}}$ is not provided in the material mill certificate and has been determined herein based on Rasmussen's (2003) recommendations. Further work

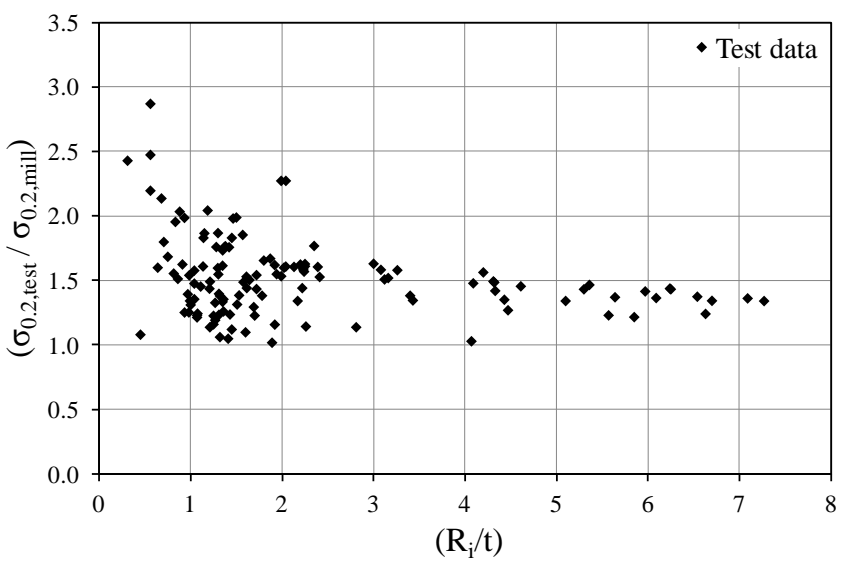

Fig. 4. Normalized measured $0.2 \%$ proof stress for the corner regions of cold-formed sections.

for accurately predicting this parameter is currently underway.

$$
\begin{aligned}
& \sigma=\mathrm{a} \varepsilon^{\mathrm{b}} \quad \text { for } 0 \leq \varepsilon \leq \varepsilon_{\mathrm{u}} \\
& \sigma=\sigma_{0.2}+\left(\frac{\sigma_{\mathrm{u}}-\sigma_{0.2}}{0.5 \varepsilon_{\mathrm{u}}-\varepsilon_{0.2}}\right)\left(\varepsilon-\varepsilon_{0.2}\right) \\
& \text { for } \quad \varepsilon_{0.2}<\varepsilon \leq 0.5 \varepsilon_{\mathrm{u}} \\
& \sigma=\sigma_{\mathrm{u}} \quad \text { for } 0.5 \varepsilon_{\mathrm{u}}<\varepsilon \leq \varepsilon_{\mathrm{u}}
\end{aligned}
$$

\subsection{Cold-work induced plastic strains}

Cold-work plastic strains are induced during both coiling/uncoiling of the sheet material and crosssection forming processes. The plastic strain components from both processes contribute to the overall strength enhancement of the flat faces of cold-rolled box sections whereas for corners of cold-rolled sections and press-braked sections, the plastic strains from the formation of the corner are generally much larger in magnitude than the plastic strains induced prior to corner forming.

The through thickness strains induced during the coiling/uncoiling processes is related to the internal coil radius and the radial location of the sheet in the coil. The critical coil radius associated with the initiation of through thickness plastic strains from sheet coiling depends on the thickness and material properties of the sheet. If the coil radius is greater than this critical radius, no plastic strains are introduced; otherwise, varying degrees of thorough thickness plastic strains are produced. As it is not possible to provide an exact measure of the plastic strains associated with the coiling/uncoiling processes, due to the unknown value of the coil radius coinciding with the as-formed member, this strain may be determined on the basis of an average coil radius, as recommended in Moen et al. (2008). From Moen et 
al.'s (2008) research, an average coil radius $\mathrm{R}_{\text {coiling }}=$ $450 \mathrm{~mm}$ is used herein.

The total plastic strain experienced by the flat faces of cold-rolled box-sections is taken as the sum of the strains from the coiling, uncoiling, formation of the circle and crushing into the final cross-section geometry - referred to as steps A, B, C and D in Rossi (2008). The strain from the sheet uncoiling and formation of the final geometry are taken as equal and opposite to the strains from coiling and formation of circular tube respectively. Hence the total plastic strains assumed to be experienced by the flat faces $\varepsilon_{\mathrm{f}, \text { total }}$ and the corner regions $\varepsilon_{\mathrm{c}}$ are given by:

$$
\begin{aligned}
& \varepsilon_{\mathrm{f}, \text { total }}=2\left[(\mathrm{t} / 2) / \mathrm{R}_{\text {coiling }}\right]+2\left[(\mathrm{t} / 2) / \mathrm{R}_{\mathrm{f}}\right] \\
& \varepsilon_{\mathrm{c}}=\left[(\mathrm{t} / 2) / \mathrm{R}_{\mathrm{c}}\right]
\end{aligned}
$$

where, $R_{c}=R_{i}+t / 2$ and $R_{f}=(b+d) / \pi$.

\subsection{Analysis of results}

The experimental database presented in Section 4.1 has been used to investigate the applicability of the two simple stress-strain models and the plastic strain measures introduced in Sections 5.2 and 5.1, respectively for predicting the strength enhancement in cold-formed sections. Numerical comparisons, including the mean and coefficient of variation (COV), of the predictions from both material stressstrain models with the test data, in terms of the predicted strength to the test strength ratio, are presented in Tables 5 and 6 for flat faces and corner regions, respectively.

Table 5. Comparison of the proposed predictive models for flat faces of cold-rolled sections.

\begin{tabular}{llcc}
\hline Predictive model & & Power model & Linear model \\
\hline \multirow{2}{*}{ All } & Mean & 1.06 & 0.96 \\
& COV & 0.19 & 0.18 \\
\hline \multirow{2}{*}{ Carbon steel } & Mean & 0.99 & 0.97 \\
& COV & 0.19 & 0.16 \\
\hline \multirow{2}{*}{ Stainless steel } & Mean & 1.08 & 0.96 \\
& COV & 0.19 & 0.19 \\
\hline
\end{tabular}

Table 6. Comparison of the proposed predictive models for corner regions of cold-formed sections.

\begin{tabular}{llcc}
\hline Predictive model & & Power model & Linear model \\
\hline \multirow{2}{*}{ All } & Mean & 1.05 & 1.04 \\
& COV & 0.15 & 0.15 \\
\hline \multirow{2}{*}{ Carbon steel } & Mean & 0.96 & 0.95 \\
& COV & 0.09 & 0.11 \\
\hline \multirow{2}{*}{ Stainless steel } & Mean & 1.08 & 1.06 \\
& COV & 0.15 & 0.15 \\
\hline
\end{tabular}

Analysis of the results shows that for both the flat faces and corner regions, the linear hardening material model gives more accurate results in terms of both the mean and the COV, than the power model. The linear hardening model and the Rossi (2008) model give the same mean of 0.96 for the flat faces of cold-rolled stainless steel and carbon steel sections with the former having a lower COV of 0.18 . As far as the corner regions of cold-formed sections are concerned, both Rossi (2008) and the proposed linear hardening model over-predict the test data, highlighting the possible over-estimation of the cold-work induced plastic strains in the corner regions. Overall, the proposed linear hardening material model with the new strain measure predictions are in good agreements with the test data and may be employed to predict the strength enhancement in cold-formed structural sections. The new proposed predictive model is simple to use in structural calculations and is applicable to any metallic structural sections.

\section{CONCLUSIONS}

A review of predictive models from the literature for harnessing the strength increase in cold-formed sections has been carried out. Two recently proposed predictive models, developed by Cruise and Gardner (2008) and Rossi (2008), were assessed extensively. Improvements to the existing models were subsequently made and a new predictive model was presented. A comprehensive database of the tensile coupon tests from existing experimental programs were used to validate the predictions from the models.

Analysis of the results showed that for the flat faces of cold-rolled stainless steel sections, the predictive model from Rossi (2008) is able to predict more accurate results, in terms of the mean value, than the predictive equation proposed by Cruise and Gardner (2008) but, has higher scatter. The results for the corner regions show that for stainless steel, the Cruise and Gardner (2008) model offers more accurate prediction of the test data with lower scatter. Also, Rossi (2008) and the modified AISI model (Gardner et al. 2010) predictions for the corner strength enhancements of carbon steel sections are in good agreement, with the former showing a lower scatter of 0.09 . It was highlighted that while the Rossi (2008) predictive model may be applied to any structural section of non-linear material, Cruise and Gardner's (2008) model is specific to austenitic stainless steel structural sections. Also, Rossi's (2008) predictive equation was considered lengthy to implement in design calculations. In order to overcome the shortcomings of these models, a linear hardening material model, with new strain measures, was proposed to predict the strength enhancement in cold-formed structural sections. The new proposed predictive model predictions are in good agreement with the test data. It is simple to use in structural 
calculations and is applicable to any metallic structural sections.

\section{ACKNOWLEDGEMENTS}

The authors are grateful to the Outokumpu Research Foundation, the Steel Construction Institute and the University of Liège for their financial and technical contributions to the project.

\section{REFERENCES}

Abdella, K. (2006) Inversion of a full-range stress-strain relation for stainless steel alloys. International Journal of NonLinear Mechanics. 41 (3), 456-463.

Afshan, S. \& Gardner, L. (In press) Experimental Study of Cold-Formed Ferritic Stainless Steel Hollow Sections. Journal of Structural Engineering (ASCE).

Ala-Outinen, T. (2007) Members with Class 4 cross-sections in fire: Work package 3. ECSC project 'Stainless steel in fire (SSIF)'. Contract no. RFS-CR-04048. The Steel Construction Institute UK.

American Iron and Steel Institute (AISI). (1996) Specification for the design of cold-formed steel structural members. American Iron and Steel Institute, Washington, D.C.

Ashraf, M., Gardner, L. \& Nethercot, D. A. (2005) Strength enhancement of the corner regions of stainless steel crosssections. Journal of Constructional Steel Research. 61 (1), 37-52.

Ashraf, M., Gardner, L. \& Nethercot, D. A. (2006) Finite element modelling of structural stainless steel cross-sections. Thin-Walled Structures. 44 (10), 1048-1062.

Coetzee, J. S., van den Berg, G. J. \& van den Merwe, P. (1990) The effect of work hardening and residual stresses due to cold work of forming on the strength of cold-formed stainless steel lipped channel section. Proceedings of the 10th international specialty conference on cold-formed steel structures, University of Missouri, USA. pp. 143-162.

Cruise, R.B. (2007) The influence of production routes on the behaviour of stainless steel structural members. Ph.D. Thesis. Department of Civil and Environmental Engineering, Imperial College London, UK.

Cruise, R. B. \& Gardner, L. (2008) Strength enhancements induced during cold forming of stainless steel sections. Journal of Constructional Steel Research. 64 (11), 1310-1316.

European Committee for standardization (CEN). (2005). Stainless steels - Part 1: List of stainless steels, EN 100881. Brussels, Belgium.

European Committee for standardization (CEN). (2005). Eurocode 3: Design of steel structures - Part 1-1: General rules and rules for buildings, EN 1993-1-1, Brussels, Belgium.

European Committee for standardization (CEN). (2007). Eurocode 9: Design of aluminium structures - Part 1-1: General structural rules, EN 1999-1-1. Brussels, Belgium.

Gardner, L. (2002) A new approach to structural stainless steel design. Ph.D. Thesis. Department of Civil and Environmental Engineering. Imperial College London, UK.
Gardner, L. \& Nethercot, D. A. (2004) Experiments on stainless steel hollow sections-Part 1: Material and crosssectional behaviour. Journal of Constructional Steel Research. 60 (9), 1291-1318.

Gardner, L., Saari, N. \& Wang, F. (2010) Comparative experimental study of hot-rolled and cold-formed rectangular hollow sections. Thin-Walled Structures. 48 (7), 495-507.

Gardner, L., Talja, A. \& Baddoo, N. R. (2006) Structural design of high-strength austenitic stainless steel. Thin-Walled Structures. 44 (5), 517-528.

Guo, Y., Zhu, A., Pi, Y. \& Tin-Loi, F. (2007) Experimental study on compressive strengths of thick-walled cold-formed sections. Journal of Constructional Steel Research. 63 (5), 718-723.

Hyttinen, V. (1994) Design of cold-formed stainless steel SHS beam-columns. Report 41: Laboratory of Structural Engineering, University of Oulu. Finland.

Karren, K.W. (1967) Corner properties of cold-formed steel shapes. Journal of Structural Division (ASCE), 93 (ST1), 401-432.

Lecce, M. \& Rasmussen, K.J.R. (2005) Experimental investigation of the distortional buckling of cold-formed stainless steel sections. Research Report R844. Centre for Advanced Structural Engineering. University of Sydney.

Moen, C. D., Igusa, T. \& Schafer, B. W. (2008) Prediction of residual stresses and strains in cold-formed steel members. Thin-Walled Structures. 46 (11), 1274-1289.

Niemi, E. \& Rinnevalli, J. (1990) Buckling tests on coldformed square hollow sections of steel Fe 510. Journal of Constructional Steel Research. 16 (3), 221-230.

Rasmussen, K. J. R. \& Hancock, G. J. (1993) Design of coldformed stainless steel tubular members. I: Columns" Journal of Structural Engineering, ASCE, 119 (8), 2349-2367.

Rasmussen, K. J. R. (2003) Full-range stress-strain curves for stainless steel alloys. Journal of Constructional Steel Research. 59 (1), 47-61.

Rossi, B. (2008) Mechanical properties, residual stresses and structural behaviour of thin-walled stainless steel profiles. PhD Thesis. University of Liège, Belgium.

Talja, A. \& Salmi, P. (1995) Design of stainless steel RHS beams, columns and beam-columns. Research note 1619. Finland: VTT building technology.

Theofanous, M. \& Gardner, L. (2010) Experimental and numerical studies of lean duplex stainless steel beams. Journal of Constructional Steel Research. 66 (6), 816-825.

van den Berg, G. J. \& van der Merwe, P. (1992) Prediction of corner mechanical properties for stainless steels due to cold forming. Proceedings of the 11th international specialty conference on cold-formed steel structures, University of Missouri, USA. p. 571-586. 